\title{
The Cross-Generation Effect of Neonatal Macrosomia in Rat Pups of Streptozotocin- Induced Diabetes
}

\author{
WILLIAM OH, NANCY L. GELARDI, AND CHUNG-JA M. CHA \\ Brown University Program in Medicine, Department of Pediatrics, Women and Infants Hospital of Rhode Island, \\ Providence, Rhode Island 02905
}

\begin{abstract}
To study the cross-generation effect of enhanced growth in macrosomic newborn rats, we induced mild hyperglycemia in 15 pregnant Sprague Dawley rats by intraperitoneal injection of streptozotocin, $35 \mathrm{mg} / \mathrm{kg}$ body weight, on the 5th d of gestation. As reported previously, we produced hyperinsulinemia and accelerated growth in the fetuses of hyperglycemic dams. We also showed that the macrosomic female pups (second generation) continued to have a higher growth rate through the first 12 wk of life. In this study, the second-generation female rats were mated with macrosomic second-generation males; they demonstrated glucose intolerance during late pregnancy and delivered pups (third generation) with higher birth weight and plasma insulin levels than the pups from control second-generation rats. When the macrosomic third-generation pups were raised under identical nutritional and environmental conditions as controls, the macrosomic rats showed accelerated growth and higher fat tissue weight during the first 12 wk of life. Furthermore, the macrosomia was associated with glucose intolerance and higher insulin to glucose ratios compared to controls. We also mated the offspring of second-generation streptozotocin-injected nonmacrosomic as well as the offspring of macrosomic pups of buffer-injected dams; none of the pups from these matings were significantly macrosomic. Therefore, we conclude that the perpetuation of obesity and possibly glucose intolerance across generations in this rat model is predominantly a result of abnormal intrauterine metabolic environment rather than genetic factor driven. (Pediatr Res 29: 606-610, 1991)
\end{abstract}

According to Pedersen's hypothesis (1), poorly controlled pregnant diabetics will have maternal hyperglycemia, which in turn induces fetal hyperglycemia and hyperinsulinemia. This abnormal metabolic and hormonal milieu results in several neonatal morbidities including neonatal macrosomia (2). Macrosomia is a result of accelerated fetal growth in the presence of an abundance of substrates and anabolic hormones such as insulin and somatomedin-c $(3-5)$. In the human $(6,7)$ and experimental models (8), neonatal macrosomia is associated with accelerated postnatal growth through adulthood resulting in an increased propensity toward obesity. In the experimental model (8), the obesity is further associated with glucose intolerance, particularly in female subjects. An intriguing question is: "Will the macrosomic female offspring of diabetic mothers become glucose in-

Received May 3, 1989; accepted February 6, 1991

Correspondence and reprint requests: William Oh, M.D., Department of Pediatrics, Women \& Infants Hospital, 101 Dudley Street, Providence, RI 02905

Supported by the Diabetes Center Grant HD 11343-09 of the National Institutc of Child Health and Human Development. tolerant during pregnancy and will their fetuses show accelerated fetal growth and abnormal glucose metabolism?" The purpose of our study is to use an experimental model to answer this question. Our hypotheses are: 1 ) the female offspring of streptozotocin-induced mild hyperglycemic rats will exhibit glucose intolerance when they attain adulthood and become pregnant; 2) these second-generation macrosomic females will produce offspring (third generation) of higher birth weight; and 3) the third-generation macrosomic offspring will exhibit postnatal growth acceleration and glucose intolerance through adulthood similar to their parents.

\section{MATERIALS AND METHODS}

The number of rats used in this study is shown in Figure 1. Mild maternal hyperglycemia was induced in 15 pregnant Sprague Dawley rats (Taconic Farm, Germantown, NY) by intraperitoneal administration of streptozotocin, $35 \mathrm{mg} / \mathrm{kg}$ body weight on the 5 th $\mathrm{d}$ of gestation. Forty-four pregnant rats were injected with $0.1 \mathrm{M}$ citrate buffer, $\mathrm{pH} 4.2$, as controls. One of the objectives of this study was to determine whether second-generation macrosomic rats born to buffer-treated dams will have an increased risk of delivering macrosomic pups (third generation). Because macrosomia is uncommon among buffer-treated pregnant rats, we injected a large number of pregnant rats $(n=44)$ with buffer to obtain enough macrosomic rat pairs for mating $($ male $=10$, female $=6)$. Maternal plasma glucose was determined on d 13,16,18,20, and 21 of gestation by cutting off the tip of the tail and squeezing it gently. Dams were allowed to deliver spontaneously and pups were weighed within $12 \mathrm{~h}$ of birth. We included in the study only those dams with litter sizes of between six and 12 pups. Pups were designated as macrosomic if their birth weight was greater than $1.7 \mathrm{SD}$ of the mean birth weight of the control dam pups. This demarcation for macrosomia is equivalent to the 90 th percentile. The mean birth weight of the control dam pups was $6.17 \pm 0.5 \mathrm{~g}$; therefore, macrosomia was defined as birth weight of $7.02 \mathrm{~g}$ or higher. All pups, both macrosomic and nonmacrosomic, from the streptozotocin and buffer dams were reared as the second-generation offspring under identical nutritional and environmental conditions. During the preweaning period, the number of pups per nursing dam was between 6 and 10 . Beyond the weaning period, rats were sexed and kept two per wood chip-bedded plastic cage with ad libitum Rat Chow (Ralston-Purina Co., St. Louis, MO) and water. The Rat Chow, Purina Formula 5001, was composed of $23.4 \%$ protein, $4.5 \%$ fat, $7.3 \%$ ash, $5.0 \%$ fiber, $49.8 \%$ nitrogen-free extract, and $10 \%$ water. Light-dark cycles of $12 \mathrm{~h}$ each and a temperature of $23-25^{\circ} \mathrm{C}$ were maintained in the animal holding room. We did not determine the daily food intake of these rats; however, in a separate study (Oh W, Gelardi NL, Cha C-J, unpublished data) to evaluate the influence of dietary intake on growth rate, we did measure the food intake by weighing the Rat 
Chow over a 24-h period on a designated day of the week; the difference in Chow weight equals intake over that 24-h period. The data (Table 1) show no difference in daily food intake of the macrosomic rats compared to controls. Rats were weighed weekly through $12 \mathrm{wk}$ of age. Our previous data on the secondgeneration rats show that the macrosomic rats have an increased growth rate during the first $12 \mathrm{wk}$, with higher epididymal fat weight in the males and salpingeal-ovarian fat pad weight in the females and glucose intolerance in the female rats. The nonmacrosomic second-generation rats showed no significant difference from controls (8).

To obtain subjects for the third-generation study, we mated the second-generation macrosomic males and females $(n=11)$, nonmacrosomic males and females $(n=9)$ in the streptozotocintreated group, and macrosomic males and females $(n=6)$ as well as nonmacrosomic males and females $(n=7)$ in the buffertreated group (Fig. 1). Pregnancy was confirmed by palpation of the fetuses at the midpoint of pregnancy. Plasma glucose concentrations were determined in both experimental and control groups at 13,16,18,20, and $21 \mathrm{~d}$ gestation via tail vein as previously described. At 19 d gestation, oral glucose tolerance tests were done on these rats. Rats were fasted for $14-16 \mathrm{~h}$ to

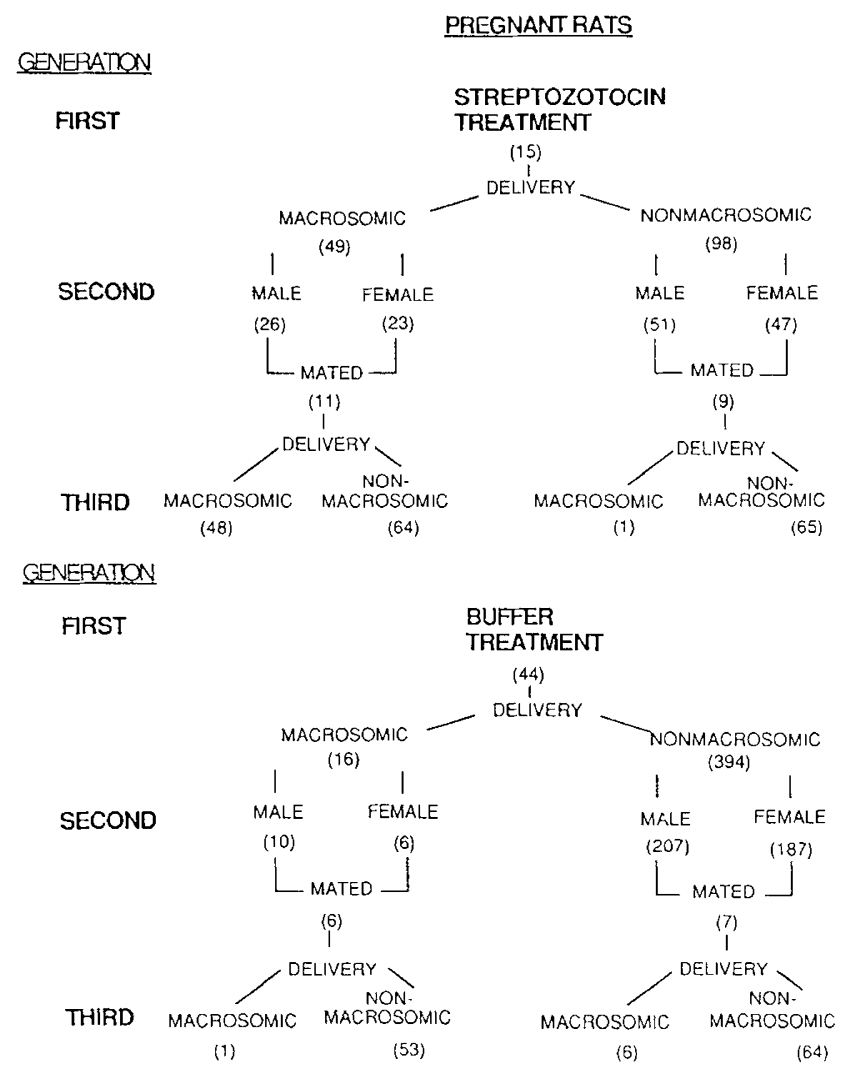

Fig. 1. Procurement of study subjects.

Table 1. Food intake during the postweaning period in male and female rats*

\begin{tabular}{|c|c|c|c|c|}
\hline \multirow[b]{2}{*}{ Age (wk) } & \multicolumn{2}{|c|}{ Male } & \multicolumn{2}{|c|}{ Female } \\
\hline & Control & Macrosomic & Control & Macrosomic \\
\hline 4 & $162 \pm 29(8)$ & $160 \pm 14(6)$ & $132 \pm 24(7)$ & $152 \pm 43(5)$ \\
\hline 5 & $152 \pm 14(6)$ & $145 \pm 16(7)$ & $149 \pm 32(8)$ & $144 \pm 11(5)$ \\
\hline 6 & $145 \pm 19(10)$ & $132 \pm 14(9)$ & $129 \pm 38(10)$ & $102 \pm 14(8)$ \\
\hline 7 & $112 \pm 20(8)$ & $106 \pm 12(6)$ & $105 \pm 25(8)$ & $104 \pm 11(8)$ \\
\hline 8 & $102 \pm 17(10)$ & $110 \pm 15(8)$ & $97 \pm 19(10)$ & $90 \pm 8(6)$ \\
\hline 9 & $82 \pm 12(8)$ & $82 \pm 17(10)$ & $97 \pm 13(9)$ & $97 \pm 20(8)$ \\
\hline 10 & $72 \pm 9(8)$ & $69 \pm 7(6)$ & $67 \pm 17(9)$ & $67 \pm 8(9)$ \\
\hline
\end{tabular}

* Values are calculated as $\mathrm{g}$ of food eaten $/ \mathrm{kg}$ body wt $/ \mathrm{d}($ mean $\pm \mathrm{SD})$. Numbers in parentheses $=n$. obtain fasting plasma glucose levels. Immediately after baseline sampling, a glucose solution, $3 \mathrm{~g} / \mathrm{kg}$ body weight, was administered orally via a polyurethane catheter attached to a syringe. Blood samples were obtained at $0.5,1.0,2.0$, and $3.5 \mathrm{~h}$ after the glucose load.

To examine the plasma insulin and glucose levels of the fetuses from these matings, 18 fetuses from the macrosomic mating group and 35 fetuses from the control mating group were delivered by cesarean section at $21.5 \mathrm{~d}$ gestation. Immediately after delivery, fetuses were killed by decapitation and blood samples were obtained for glucose and insulin determination.

The third-generation postnatal study subjects were delivered spontaneously and fetal weights were obtained within $12 \mathrm{~h}$ of delivery. The mean birth weight of control pups $+1.7 \mathrm{SD}$ was again used as the lower limit of birth weight for the designation of neonatal macrosomia. All pups were reared under the same nutritional and environmental conditions as described for the second-generation rats. At 6 and 12 wk of age, oral glucose tolerance tests were performed using the same procedure as described above. At $12 \mathrm{wk}$, rats were killed for fat weight and body composition determinations. Rats were weighed, anesthetized with ketamine, and crown-rump lengths were measured. Blood samples were then obtained via cardiac puncture. Liver and the entire fat tissue surrounding the kidneys and inguinal and epididymal areas for the males, and surrounding the kidneys, ovaries, Fallopian tubes, and inguina for the females were removed, blotted, and weighed. We labeled the fat tissue as epididymal fat for males, and perirenal-ovarian salpingeal fat for females.

Plasma glucose determinations were done by the glucose oxidase method using a YSI 23 A glucose analyzer (Yellow Springs Instrument Company, Yellow Springs, $\mathrm{OH}$ ). Plasma insulin was determined by RIA (9) (Serono Diagonostics, Braintree, MA).

Statistical analysis was done using analysis of variance with post hoc tests for group differences in weekly weight changes and oral glucose tolerance test results. Unpaired $t$ tests were used to analyze other group differences.

\section{RESULTS}

This report deals with data of second- and third-generation rats. The data for the first- and second-generation rats have been reported previously (8). As shown in Figure 2, the plasma glucose concentrations of the 11 second-generation macrosomic pregnant dams were higher than those of the seven pregnant nonmacrosomic dams from buffer-treated controls during the last half of gestation. The plasma glucose levels of the macrosomic group at $21 \mathrm{~d}$ of gestation were not different from controls. Figure 3 shows the results of the oral glucose tolerance tests of both macrosomic and nonmacrosomic dams on the 19th $\mathrm{d}$ of gestation. The fasting plasma glucose values were similar in all groups. There is an apparent discrepancy between the baseline plasma glucose concentrations in the macrosomic dams during the oral glucose tolerance test and the plasma glucose determi-

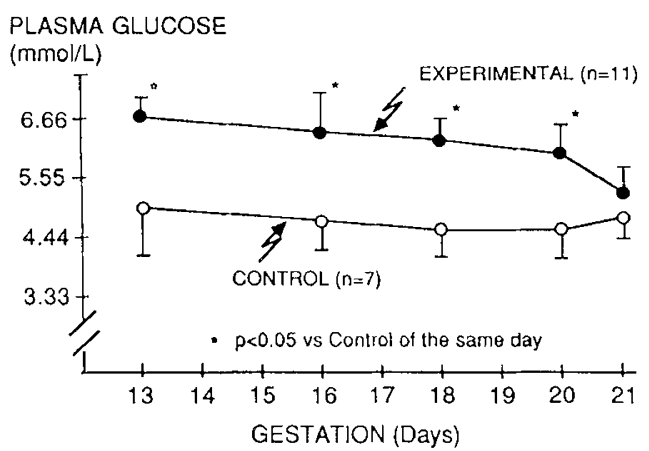

Fig. 2. Plasma glucose concentrations in the pregnant second-generation rats during the last half of gestation. 


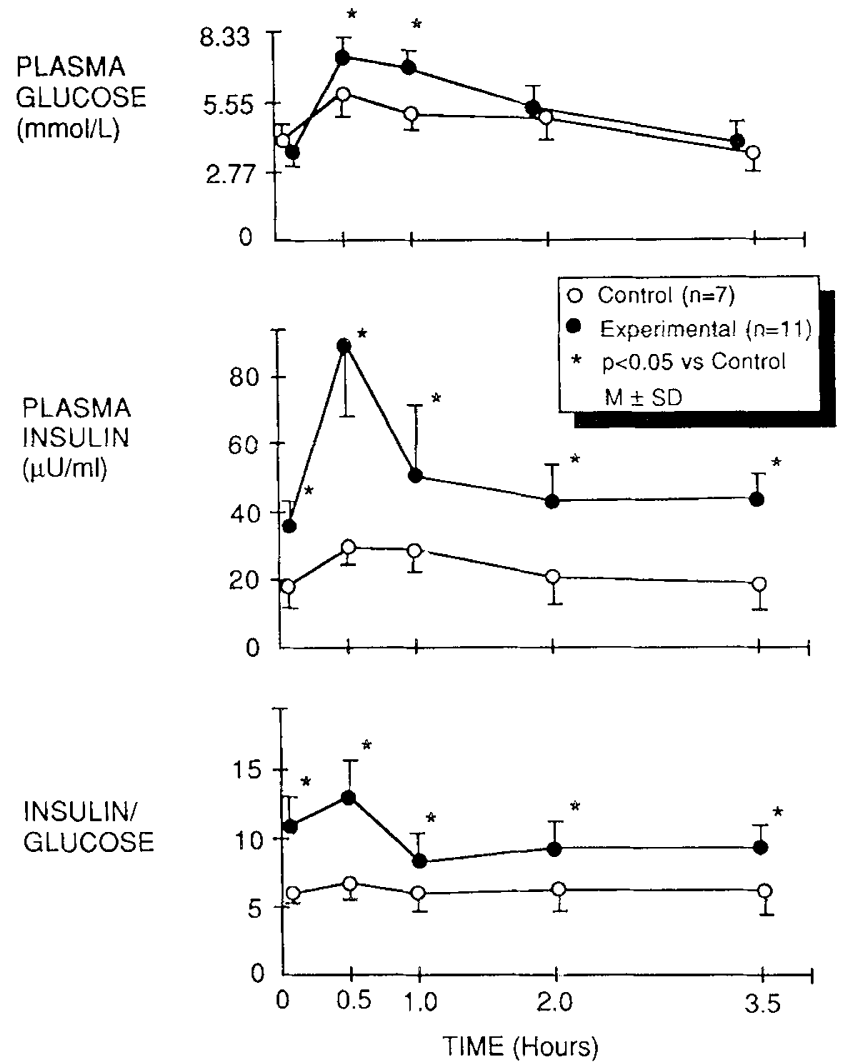

Fig. 3. Oral glucose tolerance test at $19 \mathrm{~d}$ gestation in experimental and control second-generation dams.

PLASMA GLUCOSE

$(\mathrm{mmol} / \mathrm{L})$

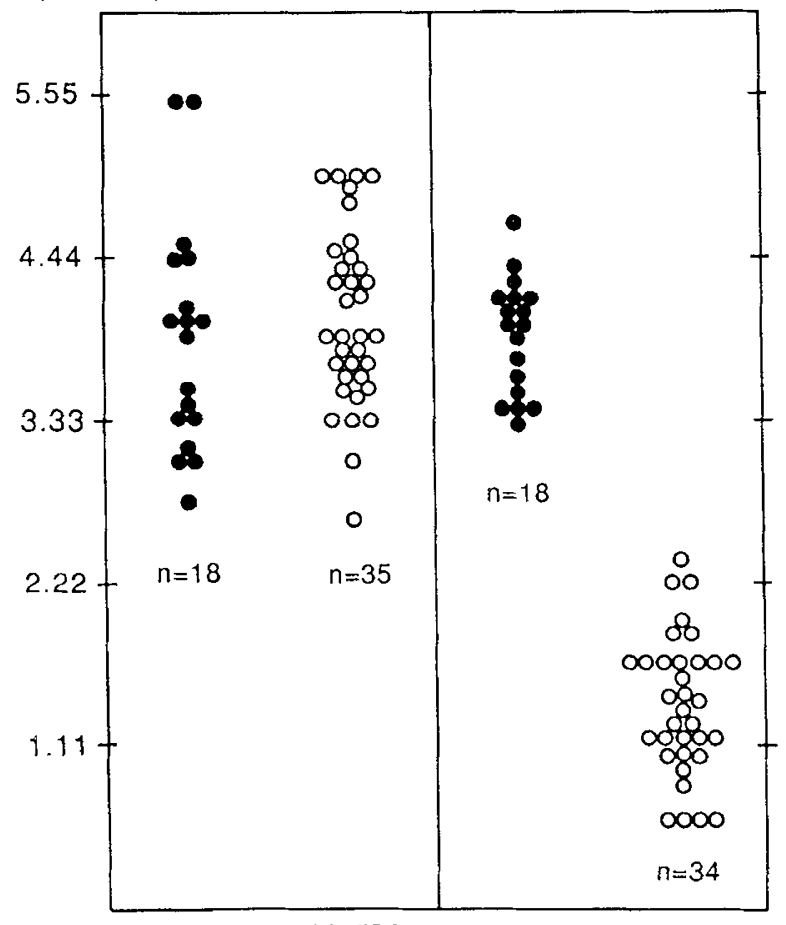

EXPERIMENTAL CONTROL EXPERIMENTAL CONTROL

Fig. 4. Plasma glucose and insulin concentrations of third-generation pups delivered by cesarean section at 21.5 d gestation.

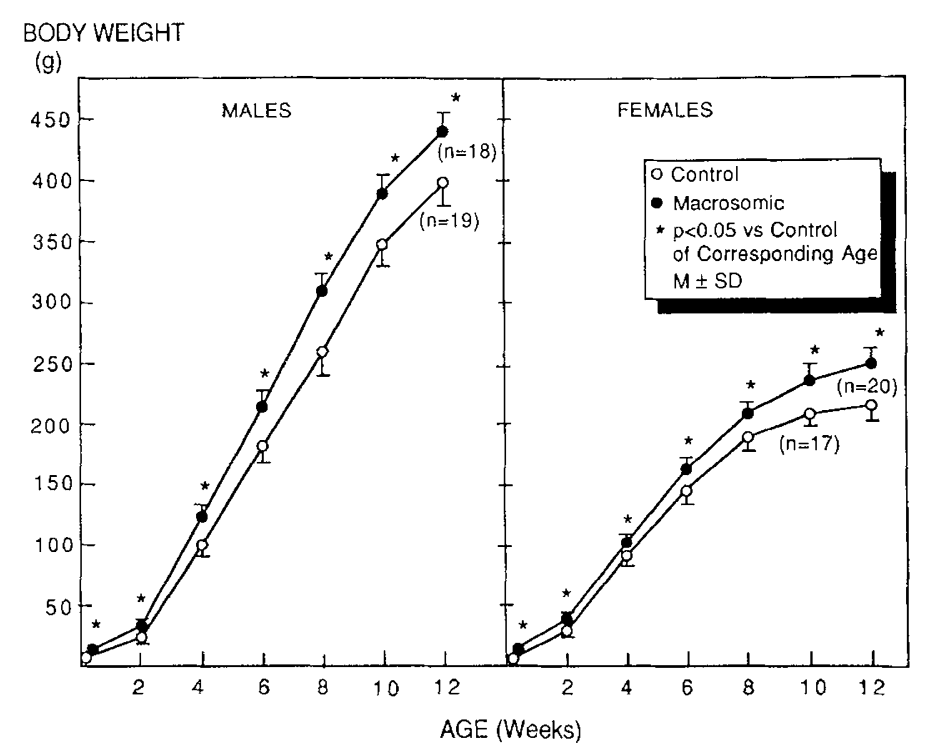

Fig. 5. Weekly body weight changes in third-generation macrosomic and control male and female rats during the first $12 \mathrm{wk}$ of life.

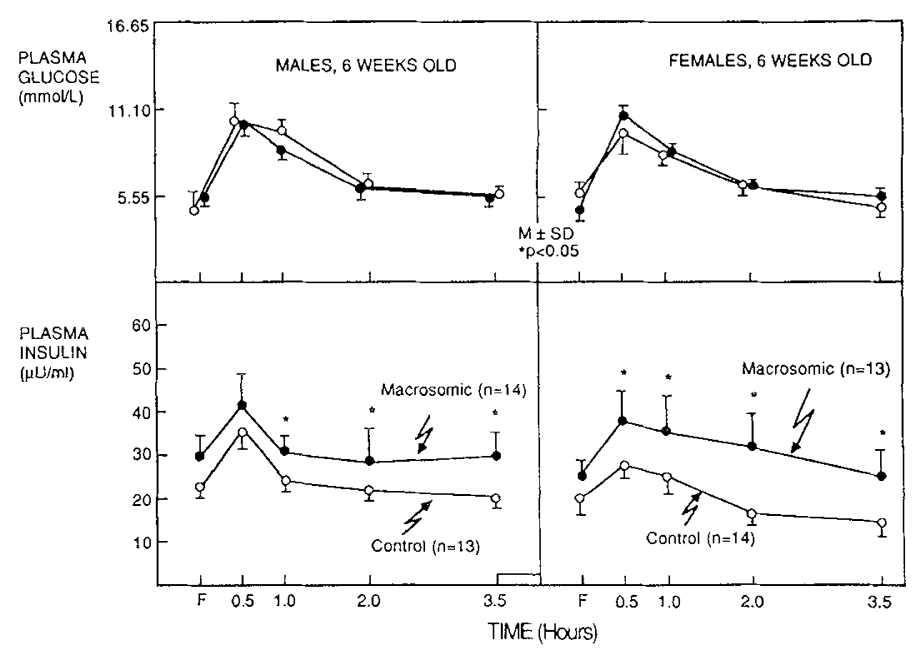

Fig. 6. Oral glucose tolerance tests in 6-wk-old male and female thirdgeneration rats. Three $\mathrm{g} / \mathrm{kg}$ body weight of glucose were given immediately after fasting blood sampling.

80

60

40

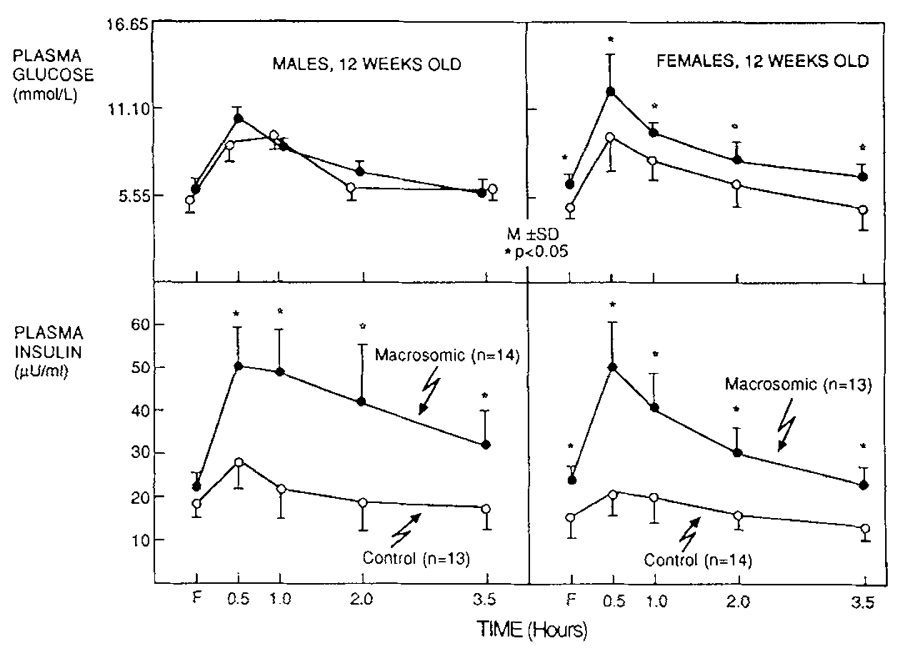

Fig. 7. Oral glucose tolerance tests in 12-wk-old male and female third-generation rats. Three $\mathrm{g} / \mathrm{kg}$ body weight of glucose were given immediately after fasting blood sampling. 
Table 2. Insulin/glucose ratio during oral glucose tolerance test (mean $\pm S D$ )*

\begin{tabular}{|c|c|c|c|c|c|c|c|}
\hline & Age (wk) & $n$ & Fasting & $0.5 \mathrm{~h}$ & $1.0 \mathrm{~h}$ & $2.0 \mathrm{~h}$ & $3.5 \mathrm{~h}$ \\
\hline \multicolumn{8}{|c|}{ Males } \\
\hline C & 6 & 13 & $4.40 \pm 0.95$ & $3.39 \pm 0.83$ & $2.61 \pm 0.47$ & $3.40 \pm 0.52$ & $3.87 \pm 0.63$ \\
\hline M & & 14 & $5.69 \pm 2.31$ & $4.04 \pm 1.24$ & $3.37 \pm 0.79$ & $4.74 \pm 2.13$ & $5.19 \pm 1.69$ \\
\hline$p$ & & & NS & NS & $<0.006$ & $<0.04$ & $<0.01$ \\
\hline $\mathrm{C}$ & 12 & 13 & $3.51 \pm 1.59$ & $2.97 \pm 0.76$ & $2.41 \pm 1.06$ & $2.76 \pm 0.76$ & $3.39 \pm 1.04$ \\
\hline M & & 14 & $5.17 \pm 0.43$ & $5.40 \pm 1.00$ & $6.22 \pm 1.47$ & $6.85 \pm 2.05$ & $6.18 \pm 1.62$ \\
\hline$p$ & & & $<0.01$ & $<0.001$ & $<0.001$ & $<0.001$ & $<0.001$ \\
\hline \multicolumn{8}{|c|}{ Females } \\
\hline $\mathrm{C}$ & 6 & 14 & $3.87 \pm 1.39$ & $2.54 \pm 0.76$ & $2.90 \pm 0.99$ & $3.03 \pm 0.43$ & $3.22 \pm 0.88$ \\
\hline M & & 13 & $3.39 \pm 0.86$ & $3.39 \pm 0.86$ & $4.34 \pm 1.98$ & $5.40 \pm 2.23$ & $5.03 \pm 1.46$ \\
\hline$p$ & & & NS & $<0.01$ & $<0.03$ & $<0.001$ & $<0.001$ \\
\hline $\mathrm{C}$ & 12 & 14 & $3.28 \pm 1.73$ & $1.57 \pm 0.43$ & $1.80 \pm 0.38$ & $2.28 \pm 0.63$ & $2.31 \pm 0.76$ \\
\hline$M$ & & 13 & $3.74 \pm 0.58$ & $4.27 \pm 0.52$ & $4.61 \pm 1.28$ & $3.96 \pm 0.67$ & $3.64 \pm 0.72$ \\
\hline$p$ & & & NS & $<0.001$ & $<0.001$ & $<0.001$ & $<0.001$ \\
\hline
\end{tabular}

${ }^{*} \mathrm{C}$, controls; $\mathrm{M}$, macrosomic.

Table 3. Body weight, length, ratio of body weight/body length, fat weight, and ratio of fat weight/body weight of males and females at 12 wk of age (mean $\pm S D)$

\begin{tabular}{|c|c|c|c|c|c|c|}
\hline & \multicolumn{3}{|c|}{ Male } & \multicolumn{3}{|c|}{ Female } \\
\hline & $\begin{array}{l}\text { Control } \\
(n=11)\end{array}$ & $\begin{array}{c}\text { Macrosomic } \\
(n=8)\end{array}$ & $p$ & $\begin{array}{l}\text { Control } \\
(n=12)\end{array}$ & $\begin{array}{c}\text { Macrosomic } \\
(n=10)\end{array}$ & $p$ \\
\hline Body wt (g) & $381.0 \pm 31.1$ & $459.3 \pm 22.3$ & $<0.01$ & $232.3 \pm 20.7$ & $262.4 \pm 13.1$ & $<0.01$ \\
\hline Body length $(\mathrm{cm})$ & $21.5 \pm 0.4$ & $21.8 \pm 1.0$ & NS & $20.1 \pm 0.8$ & $20.1 \pm 0.2$ & NS \\
\hline Body wt/body length & $17.7 \pm 1.3$ & $21.1 \pm 1.6$ & $<0.01$ & $11.1 \pm 1.0$ & $13.1 \pm 2.5$ & $<0.01$ \\
\hline Liver wt/body wt $\times 100$ & $4.0 \pm 0.5$ & $4.3 \pm 0.4$ & NS & $4.0 \pm 0.3$ & $4.2 \pm 0.5$ & NS \\
\hline Fat wt $(g)^{*}$ & $5.1 \pm 1.9$ & $12.7 \pm 2.9$ & $<0.01$ & $4.7 \pm 0.6$ & $8.9 \pm 2.0$ & $<0.01$ \\
\hline Fat wt/body wt $\times 100$ & $1.3 \pm 0.4$ & $2.8 \pm 0.6$ & $<0.01$ & $2.0 \pm 0.3$ & $3.4 \pm 0.7$ & $<0.01$ \\
\hline
\end{tabular}

* Fat wt, epididymal fat for males, peri-ovarian salpingeal fat for females.

nation done at random as shown in Figure 2. The higher baseline plasma glucose concentrations were randomly sampled in the fed state, whereas the lower baseline plasma glucose values for the glucose tolerance test reflect a 14- to 16-h fasted state. After oral glucose loading, the plasma glucose values of the macrosomic dams were significantly higher than those of the control dams at $30 \mathrm{~min}$ and at $1 \mathrm{~h}$. Plasma insulin levels of the experimental rats were higher than those of controls at all time points during the test. The calculated insulin to glucose ratios were also higher in the macrosomic group compared with the control group at all time points. Figure 4 shows the plasma glucose and insulin values of pups born by cesarean section at $21.5 \mathrm{~d}$ gestation. The plasma glucose concentrations of the third-generation pups born to macrosomic dams were similar to the third-generation pups born to control dams. However, the plasma insulin levels of the macrosomic dams' pups were significantly higher than those of the control dams' pups.

Figure 5 shows the weekly weight changes in a subgroup of male and female third-generation rats during the first $12 \mathrm{wk}$ of life. Macrosomic rats, both male and female, showed significantly higher body weights than controls (nonmacrosomic pups born to nonmacrosomic rats of buffer-injected first generation dams) on a weekly basis. A comparison of growth rates between the nonmacrosomic rats $(n=64)$ born to macrosomic dams, the macrosomic $(n=1)$ and nonmacrosomic $(n=65)$ rats born to nonmacrosomic streptozotocin-treated second-generation dams, and the macrosomic rat $(n=1)$ born to a macrosomic buffertreated second-generation dam were not done because of the small numbers $(n=1)$ in some of those groups. The growth rate and glucose tolerance test data of the macrosomic third-generation rats from buffer-treated second-generation dams $(n=6)$ were not different from their nonmacrosomic littermates $(n=$ 64) (see Fig. 1 for various groups). Figures 6 and 7 show the plasma glucose and insulin values after oral glucose loading in
6- and 12-wk-old male and female rats, respectively. At $6 \mathrm{wk}$, both male and female third-generation macrosomic rats showed significantly higher plasma insulin concentrations after glucose loading. Plasma glucose concentrations were not different between the groups. At $12 \mathrm{wk}$ of age, both male and female macrosomic rats showed a marked increase in plasma insulin concentration after glucose loading; however, only female rats showed significantly higher plasma glucose levels at various time points after glucose loading. Table 2 shows the insulin/glucose ratios during the oral glucose tolerance tests. At $6 \mathrm{wk}$, the ratios at baseline were similar between the groups for both males and females. After oral glucose loading, insulin/glucose ratios were higher in the macrosomic groups. Similar results were observed at $12 \mathrm{wk}$ of age.

Table 3 shows that at $12 \mathrm{wk}$ of age body weight was higher in the macrosomic group for both males and females, but the body lengths were similar between the groups. The macrosomic groups had higher epididymal fat in males and perirenal-ovarian salpingeal fat in females. The ratios of fat weight to body weight were greater in the macrosomic group for both males and females compared to controls.

\section{DISCUSSION}

The main purpose of our study was to document the crossgeneration effect of obesity. We asked the question, "Will the macrosomic offspring of diabetic mothers become glucose intolerant during pregnancy, and will their fetuses have accelerated fetal growth?" Our data provided an affirmative response to this question.

Using the vital statistics data from the state of Tennessee, Klebanoff and Yip (10) have shown that mothers who were low birth weight when they were born have a greater chance of delivering small-for-gestational-age infants (10). To our knowl- 
edge, whether or not this cross-generation effect of fetal growth performance occurs in large-for-gestational-age women has not been shown. Our data suggest that this phenomenon could well occur and merits epidemiologic investigation in humans. The rat pups born to mildly hyperglycemic dams who were macrosomic at birth maintained a higher weight gain postnatally (8). When they became pregnant, their plasma glucose concentrations during the last half of gestation were higher than the controls. These rats also demonstrated abnormal glucose tolerance at $19 \mathrm{~d}$ gestation. These observations closely mimic human pregnancy complicated by obesity and glucose intolerance, which is often associated with perinatal complications including fetal and neonatal macrosomia $(11,12)$.

The reasons for the fall in plasma glucose concentration at late gestation in the experimental subjects is unclear. Previous studies $(13,14)$ have suggested that increased fetal glucose utilization in late pregnancy may result in the fall of maternal plasma glucose concentrations; however, our experimental dams also demonstrated insulin insensitive glucose intolerance. Therefore, the two phenomena (fetal glucose consumption and maternal glucose intolerance) may produce opposing results with reference to maternal plasma glucose concentrations. This issue remains to be explored in future experiments.

The higher insulin to glucose ratio at various time points during the glucose tolerance tests suggests that the glucose intolerance may be a result of peripheral insulin resistance rather than a decrease in insulin secretion $(15,16)$.

Our data showing a pattern of accelerated postnatal growth in the third-generation macrosomic rats are similar to the growth pattern of the second-generation rats (8). The only difference is that in the second-generation rats the higher weight gain is in the females, whereas in the males it is not strikingly different. In the third generation, both males and females showed a similar degree of weight gain during the first 12 wk of life. Why there is a difference in the second versus the third generation from the gender difference point of view is not clear.

The oral glucose tolerance test data in the third-generation rats at 6 and $12 \mathrm{wk}$ of age are similar to those observed in the secondgeneration subjects (8). The reason for the glucose intolerance in the third generation of the current study can be explained on the basis of insulin insensitivity in obese subjects (15). The high insulin to glucose ratio at various time points after oral glucose loading, i.e. glucose intolerance in the experimental group, supports this explanation. Again, the sex difference and the degree of glucose intolerance and peripheral insulin resistance observed in the third generation as well as that seen in their parents remains to be explored.

To eliminate the possibility of genetically based selection of largeness in the subsequent generations of animals, the nonmacrosomic second-generation offspring of streptozotocin-injected dams were mated $(n=9)$. Of the resulting third-generation pups, only one was defined as being macrosomic. Additionally, the macrosomic pups of the buffer-injected dams were also mated $(n=6)$. Again, only one of the 54 third-generation pups was macrosomic. These data can be interpreted to indicate that intrauterine metabolic environment, rather than genetic factors, plays an important role in perpetuating obesity and abnormality in glucose tolerance across generations.

The clinical relevance of our current study has to do with the perpetuation of obesity across generations and its associated morbidities such as the development of hyperglycemia and adultonset diabetes. The close relationship between obesity both in the neonatal period and in adulthood with the development of glucose intolerance suggests that the amelioration of glucose intolerance can be achieved by reduction in weight gain during the developmental period. An intriguing question is whether dietary restriction in the early stage of life in the macrosomic newborn would reduce weight gain, prevent obesity, and maintain normal glucose metabolism.

\section{REFERENCES}

1. Pedersen J 1977 The Pregnant Diabetic and Her Newborn, 2nd Ed. Williams $\&$ Wilkins, Baltimore.

2. Oh W 1985 The infant of a diabetic mother. In: Nelson NM (ed) Current Therapy in Neonatal Perinatal Medicine. CV Mosby Co, Toronto

3. Hill DE 1976 Insulin and fetal growth. In: New MI, Fiser Jr RH (eds) Diabetes and Other Endocrine Disorders During Pregnancy and in the Newborn. Alan R Liss, New York, pp 127-139

4. Hill DE 1978 Effect of insulin on fetal growth. Semin Perinatol 2:319-328

5. Susa JB, Widness JA, Hintz R, Liu F, Sehgal O, Schwartz R 1984 Somatomedins and insulin in diabetic pregnancies: effects of fetal macrosomia in the human and rhesus monkey. J Clin Endocrinol Metab 58:1099-1105

6. Vohr BR, Lipsitt LP, Oh W 1980 Somatic growth of children of diabetic mothers with reference to birth size. J Pediatr 97:196-199

7. Pettitt DJ, Baird HR, Aleck KA, Bennett PH, Knowler W 1983 Excessive obesity in offspring of Pima Indian women with diabetes during pregnancy. N Engl J Med 308:242-245

8. Oh W, Gelardi NL, Cha C-J 1989 Maternal hyperglycemia in pregnant rats its effect on growth and carbohydrate metabolism in the offspring. Metabolism 37:1146-1151

9. Hales CN, Randall PH 1963 Immunoassay of insulin with insulin antibody precipitates. Biomed J 8:137-146

10. Klebanoff MA, Yip R 1987 Influence of maternal birth weight on rate of fetal growth and duration of gestation. J Pediatr 2:287-292

11. Bortz WM 1969 Metabolic consequences of obesity. Ann Intern Med 71:833

12. Pagano G, Cassader M. Massobrio M 1980 Insulin binding to human adipocytes during late pregnancy in healthy, obese and diabetic states. Horm Metab Rcs 12:177

13. Freinkel N 1965 Effects of the conceptus on maternal metabolism during pregnancy. In: Leibel BS, Wrenshall GS (eds) On the Nature and Treatment of Diabetes. Excerpta Medica. Amsterdam, pp 679-686

14. Knopp RH, Saudek CD, Arky RA, O’Sullivan JB 1973 Two phases of adipose tissue metabolism in pregnancy: maternal adaptations for fetal growth Endocrinology 92:984-988

15. Kreisbcrg RA, Boshell BR, Diplacido R 1967 Insulin secretion in obesity. N Engl J Med 276:314-319

16. York DA, Steinke J, Bray GA 1972 Hyperinsulinemia and insulin resistance in genetically obese rats. Metab Clin Exp 21:277-284 